\title{
AC 2009-2430: NCSLI'S METROLOGY AMBASSADOR OUTREACH PROGRAM
}

Georgia Harris, National Institute of Standards and Technology

Georgia Harris is the Group Leader for the Laboratory Metrology Group in the Weights and Measures Division of the National Institute of Standards and Technology. She is responsible for the Laboratory Recognition, Training, and proficiency testing of State Weights and Measures Laboratories and has been involved in metrology for more than 25 years. Prior to her work at NIST, she was a metrologist with the State of Minnesota.

Ms. Harris is also the Vice President of Learning and Development in the National Conference of Standards Laboratories, International. She has been a Board member for 13 years and is responsible for establishing the current strategic roadmap for metrology education and training and for implementing changes called for in the roadmap.

\section{Elizabeth Gentry, National Institute of Standards and Technology}

Elizabeth Gentry is the U.S. Metric Program Coordinator at the National Institute of Standards and Technology (NIST), responsible for metric resources and outreach. She is also the CO-chair of NCSLI Education Liaison and Outreach Committee.

Prior to her work at NIST, she was a metrologist with the State of Oklahoma Bureau of Standards. 


\title{
NCSLI'S METROLOGY AMBASSADOR OUTREACH PROGRAM
}

\begin{abstract}
The National Conference of Standards Laboratories, International (NCSLI) began an active outreach effort to students of all ages as a part of its Metrology Ambassador Program in 2006. A number of outreach efforts were shared at the ASEE conference in 2007. During 2007, NCSLI improved our focus on training Ambassadors, outreach resources, and outreach strategies. This paper/presentation shares effectiveness and impact about metrology outreach approaches NCSLI has tried, along with ideas about next steps that should be taken.
\end{abstract}

\section{Introduction}

Outreach approaches included providing guidance articles to the measurement community, hosting science-fair like events at measurement conferences, developing additional resources and tools for outreach to schools, inviting local professors and students to measurement conferences and regional meetings, and visiting universities.

\section{Metrology Ambassador Guidance}

In 2008 NCSLI began the development of a Metrology Ambassador program for outreach to K 12 students and early university students. The organization wrote a series of articles in its newsletter to tell people 1) How You can be a Metrology Ambassador to give them ideas about making contact with teachers 2) Interviews with Metrology Ambassadors to give them an idea of what some key people have been doing (six members were interviewed) and 3) Resources for Metrology Ambassadors to share what resources are readily available to engage their local schools.

The key factor here was that NCSLI perceived a need to teach measurement professionals how to be successful in outreach efforts to students.

\section{Effectiveness and Impact}

NCSLI has found that people who want to be Ambassadors want a complete packaged message for every audience. For example, having a measurement kit and hand-outs is not enough for some metrology professionals; they want a script and lesson plans too. Other Ambassadors demonstrate creativity and are able to effectively use the resources to supplement what they might do. Therefore, the effectiveness and impact is terrific for some, but less effective than it could be for others. NCSLI needs to find the right balance and level of effort in creating resources and providing guidance and encouragement to Ambassadors.

\section{Next Steps}

Example lesson plans, and stories of how resources have been used are needed to supplement the resources to minimize the level of oversight and support needed from the committee chairs. 
NCSLI needs to develop turn-key solutions for outreach so that when a metrology professional checks out a package or obtains resources they have what they need to be successful.

\section{Conference "Science Fairs"}

NCSLI created a number of resources and made them available to members to encourage and support active engagement in the educational communities. It held a "science fair" type event at the annual Conference to engage participants and share the new resources. The participants became familiar with resource availability and shared ideas on engaging the local schools in their areas. The Learning and Development committee followed up the event by hosting a booth in the exhibit hall so that people could follow up with additional questions and see the new resources. Approximately 100 people participated in the event and several hundred stopped by the booth for more information. The approach generated enough excitement that the committee was asked to host a similar event at another Conference in California in March 2009.

Local and national Metrology Ambassadors are recruited from the measurement science community to participate in the interactive conference session, sharing hands-on activity ideas, best practices, antidotes, and other helpful education outreach hints learned from their experiences. Conference participants learn that the opportunities and approaches to Metrology career outreach are diverse. One benefit of the Conference "Science Fair" event is that participants become familiar with the current NCSLI Metrology outreach 'toolbox' and the abundant opportunities to become a Metrology Ambassador. The opportunity for Metrology Ambassadors' to share their enthusiasm and experiences with students to inspire Conference session participants to get involved in measurement science outreach in their community is an additional benefit.

The Conference 'Science Fair' session is kicked of with hands-on measurement activity. "Metric Estimation - How Big?" is an interactive game, developed by the NIST Metric Program, which can be used by both Metrology Ambassadors and Teachers to increase student interest and knowledge in measurement science. About how many grams does a baseball weigh? Approximately how many millimeters long is a crayon? How many liters are in that water bottle? The objective of the activity is to become familiar with metric system (SI, International System of Units) measurements by practicing estimation skills using everyday household items (Figure 1). Participants work in small groups and earn points in this fun and challenging team game. 


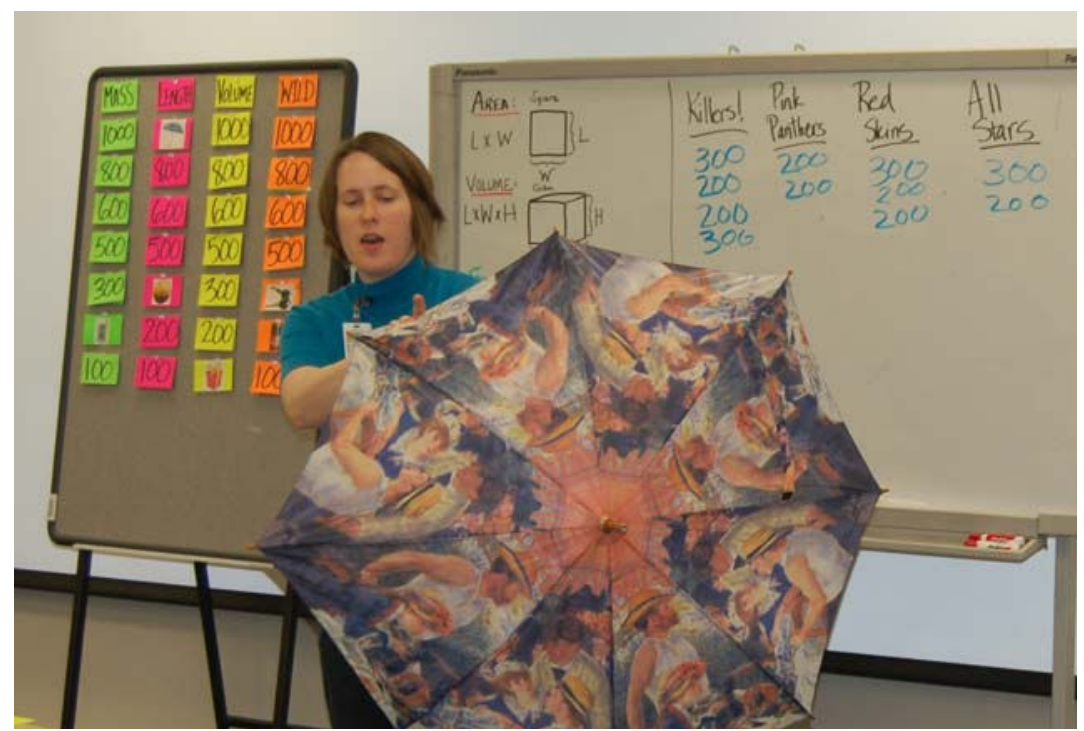

Figure 1 - Conference 'Science Fair' participants learn a hands-on activity that can be used at outreach events to familiarize students with SI units.

During the second half of the interactive Conference session, Metrology Ambassadors set-up stations, much like a carnival or science fair, around the meeting room. These volunteers share information about their experiences with Metrology education outreach activities and opportunities. Ambassadors share and distribute information at their station include: photos from outreach events, display presentations (PPT) or video describing their education activities or program, a example hands-on demonstration, quiz or game, and fliers illustrating examples of the hands-on activities or event lesson plans.

Representatives from successful Science Technology Education and Mathematics (STEM) Outreach Programs, such as the Navy Science and Technology Education Partnership (STEP), Naval Sea Systems Command (NAVSEA) Science Enrichment Program (NSEP), National Institute of Standards and Technology (NIST) Summer Institute for Middle School Science Teachers, and FLP Energy Seabrook Station Metrology Outreach Program, share their information about their efforts. Metrology Ambassadors are also invited to spend some time promoting their Outreach Program activities and/or leave materials at the NCSLI Learning and Development booth on the Conference exhibit floor.

To encourage session participants to visit each station, a 'Metrology Ambassador Passport' (Figure 2) is distributed to participants, stamped at each station, and later placed in a drawing for prizes at the end of the program. Participants also have the opportunity to give feedback, including suggestions regarding future Metrology education and outreach projects for the 164 Education Liaison and Outreach Committee. 


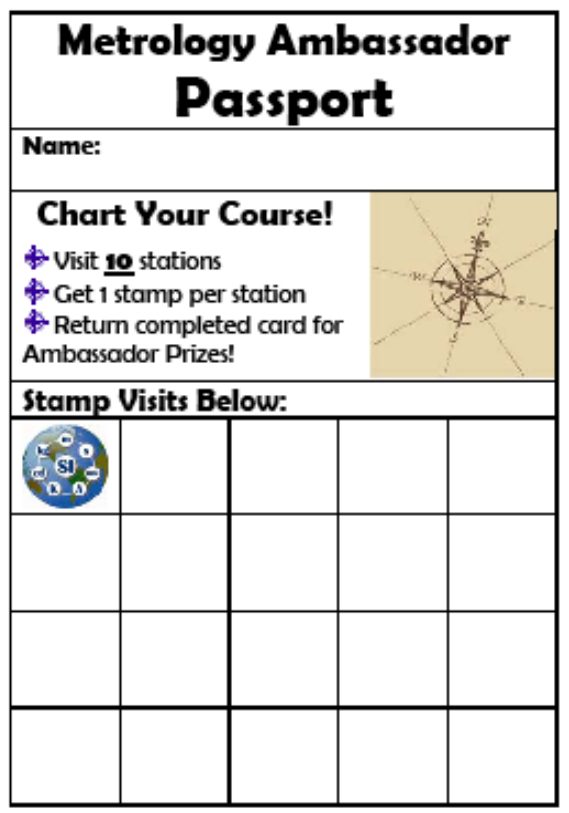

Figure 2 - Metrology Ambassador Passport.

\section{Effectiveness and Impact}

There are several levels for evaluating educational activities. Considering Kirkpatrick evaluation models, with Satisfaction as the first level, the conference "Science Fairs" have been fun, engaging, and lively. Participants are engaged and excited; they share their experiences with other metrology professionals who were not in their sessions. Evaluation forms indicate a high level of satisfaction. At the next levels, the degree of learning and application can be assessed. Several participants of these sessions have requested the resources for use at local levels and local section meetings and for sharing in their local schools. NCSLI has not received feedback yet on how the use is received at other levels. The Metric Estimation Game has been shared with teachers in the Montgomery County (MD) school district as a part of the NIST Summer Institute for Teachers program with good success. It has also been used in Montgomery, Frederick, and Baltimore county schools by Metrology Ambassadors. It is a fun session that appears to be very effective at getting adults and students thinking in metric.

\section{Next Steps}

Measuring the impact further is essential. NCSLI needs to determine how many attendees are taking what they learn at the conference Science Fair events and expanding it for other audiences. Appendix A shows the initial Event Tracking Form. Based on one response in February 2009, a representative from one session took NCSLI and NIST materials to an Expanding Your Horizon session in California and reached about 600 girls with hands-on experiments in metrology. The response was favorable. NCSLI expects that this kind of leveraging is going on regularly, but does not have the data to demonstrate effectiveness and impact. That is the next step.

\section{Outreach Resources}


NCSLI has begun developing a Metrology Ambassador Resource Toolbox to remove common obstacles to make conducting Metrology education outreach simple, easy, and efficient. The NCSLI resources are designed to help Metrology Ambassadors convey measurement science fundamentals and let students learn about careers in the Metrology profession. Metrology Ambassador are located all across North America and volunteer at diverse set of outreach venues: a presentation at a 'Career Day,' spending an hour in science classroom at your local school conducting hands-on measurement activities, inviting science teachers and students from higher education institutions with Engineering or Metrology curriculums to attend NCSLI region and section meetings, or hosting student tours of a Metrology laboratory (scheduled around special events like World Metrology Day, May $20^{\text {th }}$ ). Outreach resources must be simple to use (little learning curve), adaptable to the target audience, and rugged (frequent handling and shipping of Metrology Kits).

A centralized infrastructure is needed to distribute these resources. The NCSLI website facilitates the distribution of both electronic publications (template presentations, fliers, and articles) and the hands-on Metrology kits, which can be checked out or 'borrowed' from the NCSLI Training Aids Library Online System (TALOS). The NCSLI Corporate headquarters (Boulder, CO) ships requested items from the Training Aids Library items and other printed materials directly to Metrology Ambassadors. Metrology Ambassadors also request measurement related educational materials to supplement classroom visits with students and teachers from the NIST Metric Program. NIST has several educational handouts available in bulk so that each student can receive a copy of SI educational materials that can be downloaded and reproduced freely from the website www.nist.gov/metric.

In summary, resources that were developed or obtained include:

- "Introduction to Metrology" PowerPoint presentation that is available for download to anyone wishing to speak to schools;

- "Careers in Metrology" posters and flyers to be used as handouts during outreach events (the back side of this poster includes a poster about the Joe Simmons Memorial Scholarship); these materials were distributed to all of our Conference attendees $(1,100$ attendees from 26 countries) as well as the Measurement Science Conference attendees (about 1,000, from 11 countries);

- An "Internship" posting link on our Jobs Board;

- Six new "Measurement Kits" that our members may check out and use as hands-on tools to demonstrate measurement science in the classroom;

- Liaison with NIST Metric Program to obtain resources for teachers and students on the metric system;

- Liaison with EURAMET to distribute a publication called "Metrology - In Short" which expanded on our current liaison to obtain and distribute outreach resources; and

- Banner posters on outreach activities to use at conferences to highlight efforts and obtain additional support.

New Resources for Outreach:

- NCSLI has a current Request for Proposals to develop a "Multimedia DVD" for use as an outreach tool to teachers, students, and High School Counselors. It obtained a commitment from the American Society for Quality, Measurement Quality Division 
(ASQ-MQD), for a $\$ 10,000$ matching challenge grant for this project. NCSLI met with the board of the Measurement Science Conference (MSC) regarding funds they maintain for the National Institute of Standards and Technology Seminars that they host every year at their conference. The MSC agreed to match the ASQ-MQD challenge. NCSLI has dedicated funds in the budget for this effort and is seeking additional grants to support the effort. Proposals will be reviewed in March 2009.

- NCSLI continues to pursue financial support for another outreach tool that would be available to teachers and students. It is a "Virtual Physical Laboratory" and was developed by a scientist in the United Kingdom for use while teaching measurements in India where they had very few laboratories for hands-on experiments. The U.K. has distributed this product nation wide. It is an ideal resource for school districts where funding is inadequate to support laboratory experiments. The cost is estimated at nearly $\$ 100,000$ to fund a similar project in the U.S.

\section{Effectiveness and Impact}

NCSLI began a process at the end of 2008 to start measuring the level of effort of Metrology Ambassadors. At the 2008 conference, badge ribbons were distributed to anyone who admitted to conducting measurement outreach to their local schools. Several hundred ribbons were distributed during the conference. NCSLI wants to be able to follow up with impact, identify suggested new resources, and identify the level of diversity that is being engaged. Forms and written articles have been created to engage the Metrology Ambassadors further. See Appendix A for Ambassador Event Tracking form.

Materials that are borrowed from the Training Aids Library are tracked through loan statistics. However, the data will only tell us who borrowed the materials and in what geographical area it has been used.

\section{Next Steps}

Encouraging Ambassadors to complete the event tracking forms has been the key challenge in obtaining measures. NCSLI realizes that generating a "count" of effort provides limited feedback on outcome: i.e., it is not known whether students who are a part of metrology outreach events follow-up with education or careers in the measurement field. The Ambassador program is really too new to measure outcome at that level, but NCSLI needs to begin planning now for how it will measure and track students through the educational system.

\section{University Interactions}

NCSLI section coordinators distribute invitations to local professors and students to attend local measurement events. NCSLI currently captures this information anecdotally in its periodicals. Ambassador efforts are also reaching into the universities, with several hosting local meetings, with professors attending section meetings, and with facility and laboratory tours happening in both directions, yet again, the reports are captured anecdotally and not systematically. The authors have developed contacts with university contacts from across the countries who have expressed interest in developing courses or programs. 
One session held at the Measurement Science Conference in Anaheim, CA in March 2009 included a session with two papers covering university interactions. One paper is on "Three Case Studies on Developing Partnerships to Support Metrology Education" by Dr. Salvador Echeverria Villagomez, Centro National de Mexico, Steven R. Stahley, Cummings, Inc. and Dr. Charles Motzko, C.A. Motzko and Associates. The paper covers case studies from several universities in the United States and in Mexico where industry-government-academic partnerships have been developed or are proceeding. Another paper presented at the conference provided guidance to the government and industry participants on how best to establish academic relationships with their local community colleges: "Breaching the Proverbial Ivory Tower: A Primer on Partnering with Community Colleges" by Leslie Larrabee, a former workforce development dean with the California Community Colleges.

\section{Effectiveness and Impact}

Very few measures are in place for these early outreach efforts to the universities. In the case studies in Mexico and two in the United States, course or programs have been developed. Yet, some programs over time have also failed due to the lack of getting students interested in the field. Interestingly, while it is difficult to attract students, those community colleges with metrology programs have $100 \%$ placement of their students, most often before the students graduate. It appears that if the school can draw adequate numbers of students, the students and local industry will benefit.

\section{Next Steps}

One of the goals for partnership efforts is to create guidance materials for representatives who are reaching out to their local schools to address developing programs from the industry perspective and from the academic perspective that identify the unique concerns of both parties. The key concern for industry is that students graduate with adequate knowledge and skills for the workplace. The key concerns for the universities have been 1) generating adequate interest to keep a critical mass of students in the programs; 2) addressing the expense of maintaining handson calibration/metrology laboratories; and 3) finding suitable instructors with the essential knowledge of metrology concepts and procedures who are also adept and effective teachers. How to address these concerns needs to be practical and straightforward to enable nonacademicians to approach the academic environment successfully.

Another goal is to conduct research in the academic-industry partnership realm in the metrology community to determine best practices that can be shared and put into practical guidebooks for others to follow.

\section{Conclusions}

Many measures of effectiveness, impact, and next steps are pending as data is still being collected from the NCSLI community. Based on early responses, materials and opportunities are well received and NCSLI is on the right track for metrology outreach. The biggest challenges are 1) to provide turn-key guidance for all potential Ambassadors with the resources that are available and 2) to find more effective ways to gather the data that demonstrates effectiveness and impact. 


\section{Appendix A \\ Ambassador Event Tracking}

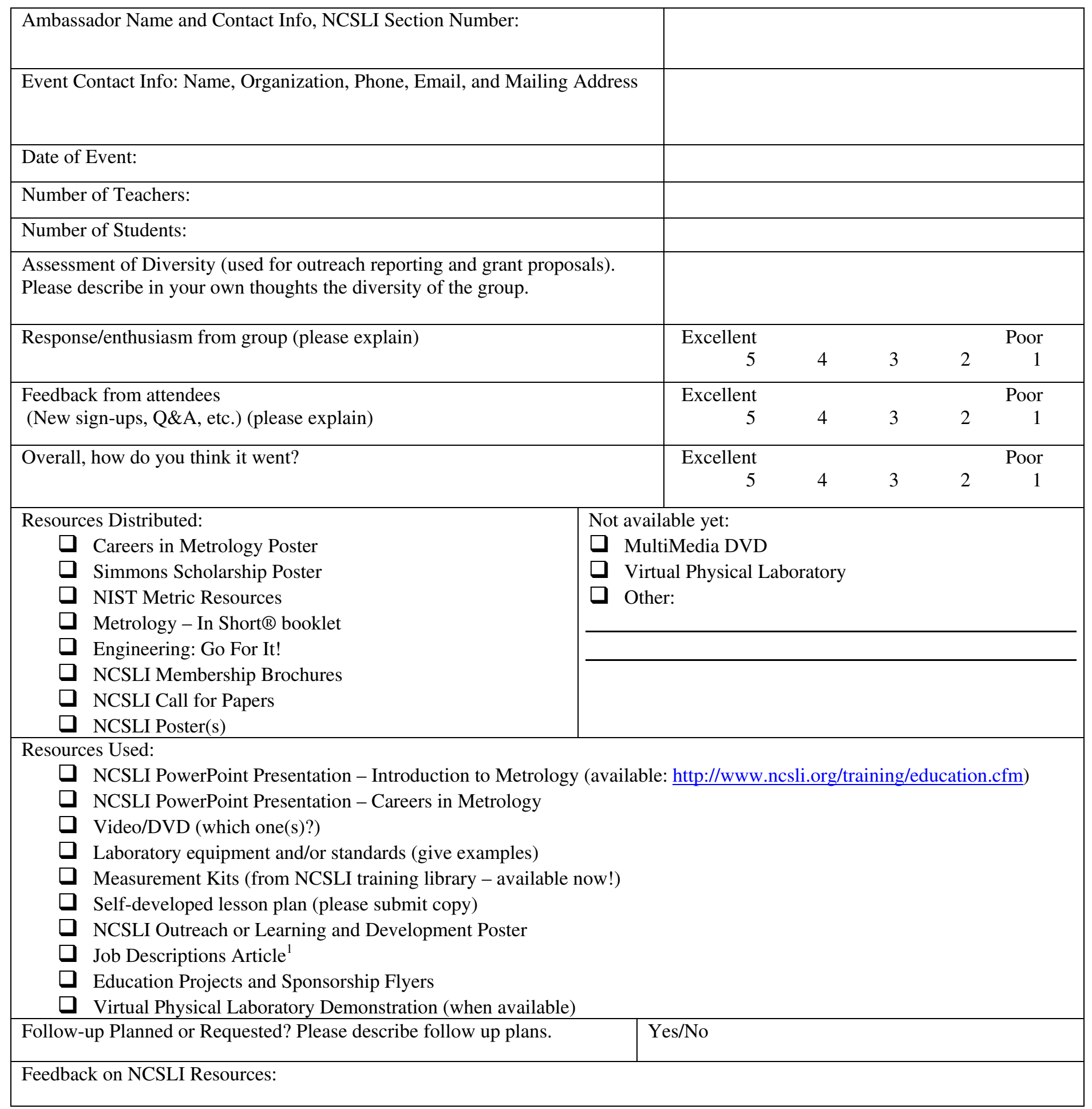

\footnotetext{
${ }^{1}$ The Metrology Job Description Initiative: NCSLI and ASQ Partnering for the Future, Christopher L. Grachanen, Measure Journal, June 2007, Chris.Grachanen@ hp.com
} 